DOT/FAA/AM-14/8

Office of Aerospace Medicine

Washington, DC 20591

\title{
Using Biodata to Select Air Traffic Controllers
}

Linda G. Pierce

Dana Broach

Cristina L. Byrne

M. Kathryn Bleckley

Civil Aerospace Medical Institute

Federal Aviation Administration

Oklahoma City, OK 73125

October 2014

Final Report 


\section{NOTICE}

This document is disseminated under the sponsorship of the U.S. Department of Transportation in the interest of information exchange. The United States Government assumes no liability for the contents thereof.

This publication and all Office of Aerospace Medicine technical reports are available in full-text from the Federal Aviation Administration website. 
Technical Report Documentation Page

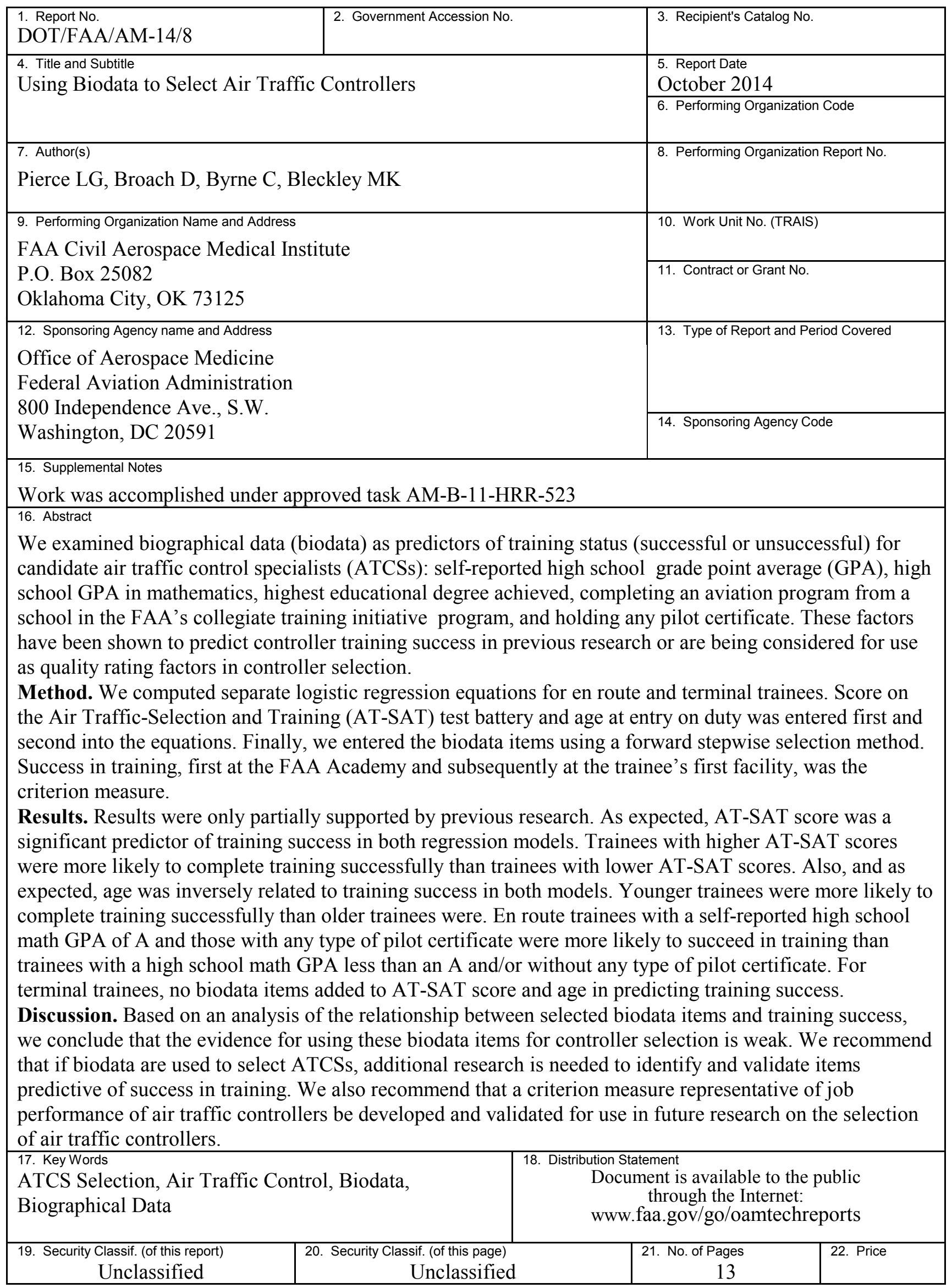

Form DOT F 1700.7 (8-72)

Reproduction of completed page authorized 



\section{ACKNOWLEDGMENTS}

Research reported in this paper was conducted under the Air Traffic Program Directive/Level of Effort Agreement between the Human Factors Division (ANG-C1), FAA Headquarters, and the Aerospace Human Factors Research Division (AAM-500) of the Civil Aerospace Medical Institute.

The opinions expressed are those of the authors alone, and do not necessarily reflect those of the Federal Aviation Administration, the Department of Transportation, or federal government of the United States.

Address correspondence concerning this report to Linda Pierce, Aerospace Human Factors Research Division (AAM500), P.O. Box 25082, Oklahoma City, OK 73125. Email: linda.pierce@faa.gov. 



\section{Contents}

\section{USING BIODATA TO SELECT AIR TRAFFIC CONTROLLERS}

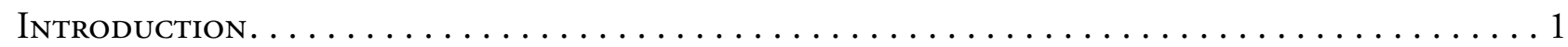

FAA Interest in Biodata. ....................................

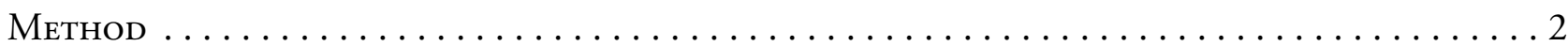

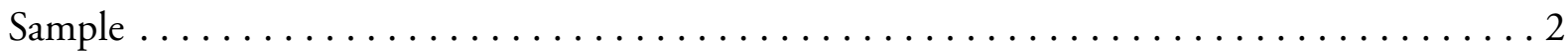

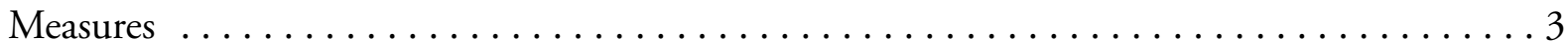

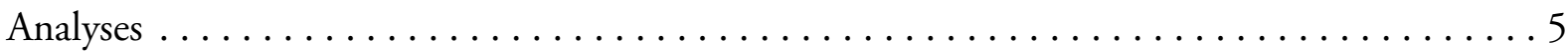

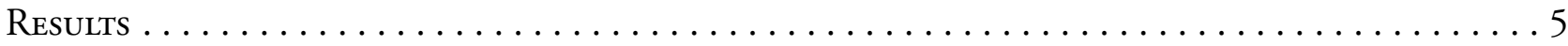

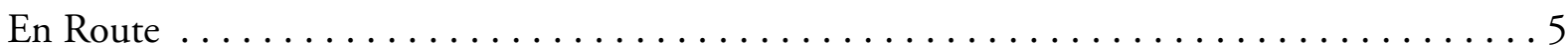

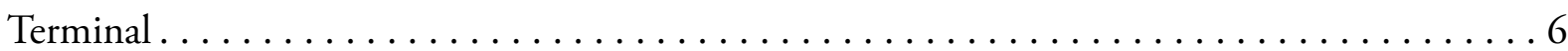

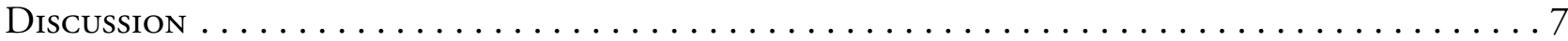

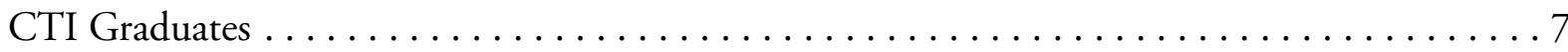

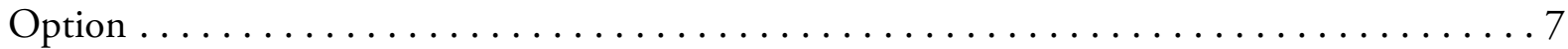

Limitation. ....................................... 8

Conclusions.................................................. 9

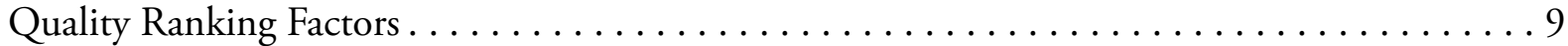

College Degree........................................

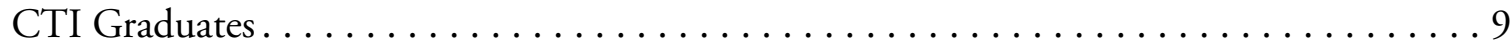

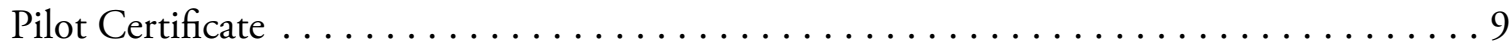

Biodata Usefullness . . . . . . . . . . . . . . . . . . . . . . . . . . . . . 9

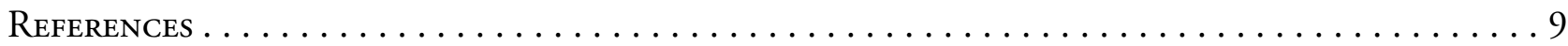





\section{Using Biodata to Select Air Traffic Controllers}

\section{INTRODUCTION}

The selection of air traffic control specialists (ATCSs; referred to as controllers) has been the subject of on-going research by the Federal Aviation Administration (FAA) from its beginnings in 1958. Aptitude, personality, and biographical information, or biodata, have all been investigated, with findings spanning three generations of U.S. controllers. In current practice, the aptitude of potential controllers is assessed with the Air Traffic-Selection and Training (AT-SAT) test battery.

The AT-SAT is a computerized aptitude test of cognitive abilities, skills, and other personal characteristics identified through formal job analysis as being required at the time of entry into the controller occupation (Ramos, Heil, \& Manning, 2001a, 2001b). AT-SAT includes seven cognitively loaded sub-tests (see Broach et al., 2013, for a brief description of AT-SAT sub-tests). Currently, personality tests are not used, and until most recently, the FAA did not use biodata scales to select controllers. In 2014, the FAA began using a biodata assessment, developed under contract for the FAA Office of Human Resource Management in Washington, DC, to screen applicants. Those passing the assessment and meeting other requirements (e.g., U.S. citizen, no older than 31) were then recommended for AT-SAT testing. In previous research by the FAA's Civil Aerospace Medical Institute (e.g., Collins, Nye, \& Manning, 1990; Nye, Schroeder, \& Dollar, 1994), both personality tests and biodata scales have been shown to predict ATCS training performance.

For example, in analyzing data gathered from 1985 through 1987, Collins et al. (1990) found that having experience as a controller, primarily in the military, and/or holding a pilot's certificate predicted FAA Academy training performance of newly hired controller trainees. Pierce, Williams, Broach, and Bleckley (2013b) analyzed data gathered from 1986 through 1992, which slightly overlapped with and extended the Collins et al. (1990) sample and found a similar relationship between FAA Academy training success and trainees having air traffic control experience and/or holding a pilot's certificate. They also found that trainees with an instrument flight rating were more likely to pass FAA Academy training than those without a rating. Other researchers have found high school (HS) grade point average (GPA) and HS grades in mathematics and physical science (VanDeventer, Collins, Manning, Taylor, \& Baxter, 1984) to predict FAA Academy controller training performance.

Conversely, attending college or receiving a college degree has not been shown to have a positive relationship with controller training success (Collins et al., 1990). In fact, in a study designed specifically to address the impact of education on controller success, defined as graduation from Academy training and retention on the job three to four years after Academy training, Cobb, Young, and Rizzuti (1976) found college graduates to attrit from controller training at a higher rate than HS graduates (for a review, see Collins, Boone, \& VanDeventer, 1981). Finally, age has been a consistent and powerful (inverse) predictor of training performance. Despite restrictions in range, due to a maximum age at entry policy, younger rather than older controllers had higher odds of success in initial training (Cobb, Lay, \& Bourdet, 1971; VanDeventer et al., 1984; VanDeventer, Taylor, Collins, \& Boone, 1983). As measured, in training, on-the-job, and in simulations, the relationship between age and success as an ATCS has been observed in different samples of controllers over an extended period-of-time (as examples see Cobb et al., 1971; Heil, 1999a; Heil, 1999b; Pierce et al., 2013b).

Recently, Dean and Broach (2012) and Broach (2012) developed and validated an empirically keyed, response-option scored biodata scale, the Controller Background Assessment Survey (CBAS), for use in selecting controllers. Using the CBAS, they found biodata to account for additional variance, beyond the variance accounted for by AT-SAT, in predicting supervisory job performance ratings (Dean \& Broach, 2012) and controller core technical skills (Broach, 2012). However, to date, researchers have not examined CBAS as a predictor of controller training performance. Recently, however, the FAA's Office of Human Resource Management in Washington, DC, used selected items from the CBAS and other biographical questionnaires developed by researchers at the Civil Aerospace Medical Institute (CAMI) to screen applicants for hiring as FAA controllers. Although CAMI researchers found the CBAS and other biodata scales to add incrementally to aptitude scores in predicting controller performance as measured, among other things, as success in training, supervisory ratings, and technical proficiency of controllers, they have not examined biodata as a method for screening applicants prior to any other form of assessment such as aptitude testing.

\section{FAA Interest in Biodata}

Two recent events within the FAA have led to renewed interest in biodata as a predictor of controller training performance. First, the FAA commissioned an independent review panel (IRP) to consider strategies for improving controller selection, training, and placement (Barr, Brady, Koleszar, New, \& Pounds, 2011). A number of the IRP's recommendations, now called "Quality Rating Factors" (QRFs), relate to the background or previous experience of controller candidates to select ATCSs. The measures of these QRFs could be legitimately referred to as biodata. The IRP initially recommended developing a model for ATCS selection based on candidate scores on six differentially weighted components. A component of the model was prior collegiate experience. The IRP recommended that the FAA award points to applicants toward selection based on college GPA as well as type of college attended. The panel also recommended awarding applicants with higher college GPAs more points than applicants with lower college GPAs. Attendance at a college or university 
within theFAA's air traffic-collegiate training initiative (AT-CTI) program also resulted in an award of additional points to the applicant. Points were awarded based on the FAA's assessment of the capabilities for teaching air traffic basics at the AT-CTI college or university.

Currently, the IRP's proposed QRFs include having a college degree; holding certificates evidencing experience as an aircraft pilot, flight instructor, aircraft dispatcher, flight navigator, or aircraft mechanic; and having prior experience as an air traffic controller. According to the IRP, these QRFs could be used to rate and rank (from high to low) applicants. The IRP recommended that the FAA incorporate these factors into its air traffic controller recruitment and selection processes. These factors were not based on empirical research results, although the IRP expressed interest in gathering data to determine the best balance among the different ranking factors (Anthony Chu, personal communication, August 23, 2012).

The second event was a recent examination of adverse impact in controller selection for certain protected groups in controller selection. The concern was the use of the AT-SAT in selecting controllers. AT-SAT has been found to be a hiring "barrier" for African-American, Hispanic/Latino, and female applicants (Outz \& Hanges, 2012). In other words, more African-American, Hispanic/Latino, and female candidates were screened out of the hiring process, based on AT-SAT scores, than were nonminority applicants.

This is not altogether surprising, given that aptitude or cognitive tests have often been found to present hiring barriers and result in differential hiring for protected groups when used for selection (Bobko \& Roth, 2013; Hough, Oswald, \& Ployhart, 2011; Sinha, Oswald, Imus, \& Schmitt, 2011). However, AT-SAT has been found to be a valid predictor of both training and job performance of controllers (Broach et al., 2013). The issue is how to reduce adverse impact in controller hiring and still maintain a valid process for selecting the best-qualified applicants for the job. One such strategy might be to use biodata to supplement cognitive testing in selecting controllers.

In previous research, biodata have been found to be effective predictors of job performance (see Schmidt \& Hunter, 1998) in many cases, without adverse impact (see Breaugh, 2009; Imus, et al., 2011). Criterion-related validity coefficients for biodata are in the .40 to .50 range (see Dean \& Russell, 2005; Mumford, Barrett, \& Hester, 2012). However, in regard to adverse impact, in a recent review, Bobko and Roth (2013) caution that much of what we know about biodata and subgroup differences is based on incumbent studies and that the average of subgroup differences may be much higher if assessing applicants or correcting for known range restriction. As evidence, they site Dean's 1999 dissertation research in which an estimate of standardized subgroup differences ( $d$ ) for biodata was .73 for an air traffic controller sample after accounting for range restriction (see Bobko \& Roth, 2013). Bobko and Roth (2013) estimated the true $d$ for biodata to be in the .39 range. However, it is probably the type of job assessed, as well as the items used to predict performance, that will influence the likelihood and degree of subgroup differences in biodata (Hough et al., 2001; Imus et al., 2011).

Researchers have also found biodata to predict performance over 10-20 years when there are no marked changes in life experiences or the job (Stokes, 1999). However, it is generally the case that the contextual nature of biodata will require that items be revalidated every five to seven years (Mumford \& Whetzel, 1997) to determine if they continue to be useful predictors. Previous FAA biodata research was based on two generations of controllers: those hired in the 1960s and 1970s and those hired following the 1981 controller strike (e.g., Cobb \& Nelson, 1974; Collins et al., 1990; VanDeventer et al., 1984; VanDeventer et al., 1983). Even the more recent Pierce et al. (2013b) study assessing prior experience in air traffic controller selection analyzed data captured from controllers hired from 1986 to 1992 . The controllers hired in the 1980s and the participants in the majority of the FAA's research on the predictive potential of biodata are reaching mandatory retirement age, and the FAA is presently hiring the next generation of controllers. Thus, there is a need to determine if factors previously found to predict training performance of candidate controllers would continue to predict the training performance of this generation of controllers.

The current effort aims to extend previous research in which biodata were used to predict candidate controller training performance to this next generation of controllers and, in so doing, contribute to the FAA's decision about the use of QRFs and inform interventions to eliminate adverse impact, while maintaining a valid selection process. Our goal is to determine if biodata can be used to improve prediction of candidate controller performance at both the FAA Academy and in facility-based training superior to what is achieved using AT-SAT.

\section{Sample}

\section{METHOD}

The sample for this study was a group of candidate air traffic controllers hired by the FAA and entering the FAA Academy from February 2007 through December $2011(N=2,662)$. The sample was $81 \%$ male. To be included in this sample, candidate controllers must have passed AT-SAT during the application process and must have completed the Biographical Questionnaire (BQ), a self-report instrument used to gather data on the candidate's prior life history, as a participant in research at CAMI, while attending controller training at the FAA Academy. The sample did not include candidate controllers meeting FAA hiring qualifications as military air traffic controllers because they do not take AT-SAT.

We divided candidate controllers into groups based on the type of facility (referred to as option) to which each was assigned prior to attending training at the FAA Academy. The two options are air route traffic control centers (ARTCCs), commonly referred to as en route centers, and terminal facilities. During the timeframe of this study, applicants selected to attend training were offered a position based on a vacancy at a specific facility (option and location). Hiring was contingent on the applicant accepting the position-specific offer. 
Time required to complete training varies by option and within options by facility level, based on the volume and complexity of the air traffic. Within the terminal option, most facilities are one of three types: airport traffic control towers with radar, terminal radar approach control (TRACON) facilities, or combined tower with radar and TRACON facilities. Controllers within terminal facilities organize the flow of air traffic into and out of airports. As air traffic leaves the terminal airspace, the responsibility for control transfers to an en route center. Trainees at terminal facilities usually on average complete on-the-job (OJT) training and become certified professional controllers (CPCs) more quickly than en route center trainees.

As indicated in the FAA's (2014) most recent controller workforce plan, the training target time by size of terminal facility is 17 months for small (levels 4-6), 24 months for medium (levels 7-9), and 29 months for large (levels 10-12) facilities. The training target time for all en route centers is 36 months. Most en route centers are classified as level 12 facilities. A description of the type and level of FAA air traffic control facilities can be found in the FAA's Controller Workforce Plan (2014). The Controller Workforce Plan, generally updated yearly, presents the FAA's strategy for hiring, placing, and training controllers to meet the demands of air traffic.

The outcome measure in this study was training status. We used the Air Traffic Control National Training Database (ATC NTD; FAA, 2011) to determine the training status of each of the 2,662 trainees in our sample (as of June 2014). In Table 1, we present the outcome data using categories defined by the FAA for use in the ATC NTD. The category groupings are (1) completed, (2) unsuccessful (facility fail), (3) in progress, (4) transfer, and (5) unsuccessful (other). A majority of trainees in our sample successfully completed training at en route centers (54.4\%) and terminal facilities (63.0\%) and became CPCs. The ATC NTD unsuccessful (facility fail) category includes trainees that failed training at the FAA Academy or at their first facility, as well as trainees that were transferred to a lower level facility before completing training at their first facility. Slightly more en route $(23.7 \%)$ trainees were unsuccessful than terminal $(19.1 \%)$ trainees.

Also, and as shown in Table 1, a larger percentage of en route $(10.9 \%)$ than terminal $(4.8 \%)$ trainees were still in training as of June 2014. Trainees may also have transferred from their first facility or been unsuccessful and left training for reasons other than performance. The transfer category is separate from the transfer lower category in that the FAA considers the transfer to a lower category a training failure, whereas a transfer is not. The trainee generally makes requests for transfer. There are many reasons why trainees may request a transfer. Trainees may apply for and be selected for a trainee position at another facility before completing training at their first facility. They also may request a transfer in response to a verified hardship, family emergency, etc. The unsuccessful (other) category is for trainees that did not complete training; however, lack of success was not due to poor performance but rather some other issue, such as failing a medical exam or security screening, retirement, or even death.

Only those trainees that completed training successfully or were unsuccessful in training were included in the regression analyses. Excluding the other trainees, there were 2,138 participants available for the analyses. In the final sample, 936 (43.8\%) were assigned to an en route center and 1,202 (56.2\%) to a terminal facility.

\section{Measures}

There were seven predictors and one criterion measure used in this study. The predictors were trainees' AT-SAT score, age at entry on duty, and responses to five questions from the biographical questionnaire on the education and background experiences of the trainees. We selected each of these items for study either because researchers had found a relationship between an item and controller performance in prior studies or because the IRP had recommended use of the item in controller selection. The criterion measures used in prior studies varied based on the objectives of the research or availability of controller performance data. For our criterion measure, we used training outcome data from both the FAA Academy and the NTD to determine the training status (successful or unsuccessful) of the trainees in our sample as of June 2014. We describe each predictor and the criterion measure below.

AT-SAT. The FAA uses AT-SAT in the hiring of all applicants except, in some cases, those hired based on their previous experience as air traffic controllers (primarily prior military controllers). For those that take AT-SAT, the FAA uses category ranking in the selection process. Applicants with AT-SAT composite scores of less than 70 are not qualified for consideration for employment. The mean AT-SAT score for the sample $(N=2,138)$ was 91.43 $(S D=5.96)$. There was little difference between the average AT-

Table 1. Training Status as of March 2014

\begin{tabular}{lccc}
\hline Outcome & En Route & Terminal & Total \\
\hline Successful & $652(54.4 \%)$ & $923(63.0 \%)$ & $1,575(59.2 \%)$ \\
Unsuccessful & $284(23.7 \%)$ & $279(19.1 \%)$ & $563(21.1 \%)$ \\
In Training & $130(10.9 \%)$ & $70(4.8 \%)$ & $200 \quad(7.5 \%)$ \\
Transfer & $63(5.3 \%)$ & $99(6.8 \%)$ & $162 \quad(6.1 \%)$ \\
Other & $69(5.8 \%)$ & $93(6.3 \%)$ & $162 \quad(6.1 \%)$ \\
\hline Total & 1,198 & 1,464 & 2,662 \\
\hline
\end{tabular}


SAT score of trainees assigned to an en route center $(M=91.52$, $S D=6.03)$ or terminal facility $(M=91.36, S D=5.91)$.

Age at Entry on Duty. With few exceptions, and as described in the U.S. Office of Personnel Management qualification standards for the ATCS occupation, applicants may not have reached their $31^{\text {st }}$ birthday by the time a tentative job offer is accepted. We used age of candidate controllers when entering the FAA Academy as a predictor of training status in the analyses. Although the FAA cannot use age at entry as a factor in selecting candidate controllers, it consistently accounts for a significant portion of the variance in predicting controller performance-related criteria. If we excluded age from the analyses, one or more of the biodata items may predict training status merely due to its association with age. In other words, age might act as a proxy and mediate the relationship between a biodata factor and training status in our models. Thus, we included age in our analyses. We could not determine at what age nine of the trainees in our sample entered training, so the average age for the remaining 2,129 trainees (931 en route center trainees; 1,198 terminal facility trainees) in our sample was $25.98(S D=2.83)$. There was little difference between the average age of trainees assigned to an en route center $(M=25.96, S D=2.83)$ or terminal facility $(M=26.00, S D=2.84)$.

Biographical Questionnaire (BQ). We used the BQ to gather information on the education and background experiences of trainees. The BQ is a self-report instrument used by CAMI to gather data on the prior life history of trainees that have just entered Academy ATC training. Farmer (2002) provides an overview of the development and use of the BQ to predict controller performance and attrition. BQ items selected for analysis were those shown to either predict the training performance of candidate controllers in the past and/or to assess a subset of the proposed quality ranking factors. The BQ items used in the current analyses were 1) HS GPA, 2) HS math GPA, 3) highest educational degree achieved, 4) having earned a degree in aviation at a college or university approved by the FAA under the Collegiate Training Initiative (CTI; see Pierce, Bleckley, \& Crayton (2013a) for more information on the CTI program), and 5) holding a pilot's certificate. The response rates varied by BQ item assessed. Other items that had shown a relationship with previous training performance, such as having military experience and experience in controlling air traffic using instrument and visual flight rules, were excluded from the analyses primarily because many of the candidate controllers with these experiences were hired as former military controllers. They had not taken AT-SAT and thus, were not part of the candidate sample used for these analyses.

FAA Training Status. The criterion for our analyses was training status (successful or unsuccessful) at the FAA Academy and in OJT at the first field facility assigned. We used FAA Academy records to determine the status of successful and unsuccessful trainees at the FAA Academy. We used the FAA ATC NTD to determine the training status of developmentals at the first field facility. Training success involves certifying on all control positions required at the facility, which allows the controller to work traffic independently, without oversight, at any of those positions. When training is successfully completed, the trainee becomes a Certified Professional Controller.

Unsuccessful training status includes FAA Academy failures and trainees that either failed facility training or were transferred to a lower-level facility from their first facility. Of the 2,138 trainees in our sample, the majority at both en route centers and terminal facilities were successful (see Table 2). Overall, slightly more than one-fourth of the trainees were unsuccessful. However, a chi-square analysis indicated that there was a significant association between the option to which a trainee was assigned and the likelihood of succeeding in training $\left(\chi^{2}(1)=13.79\right.$, $p<.001)$. Trainees assigned to a terminal facility were successful more often than expected (923/886) and unsuccessful less often than expected (279/317). The relationship reversed for trainees assigned to an en route center. Trainees assigned to an en route center were successful less often than expected (652/690) and unsuccessful more often than expected (284/247). The odds that a trainee assigned to a terminal facility would succeed were 1.44 times higher than for a trainee assigned to an en route center. Thus, we conducted separate analyses for trainees assigned to en route centers and terminal facilities.

Table 2. Training Status by Option

\begin{tabular}{lccc}
\hline Outcome & En Route $(n=897)$ & Terminal $(n=1,185)$ & Total $(\mathrm{n}=2,082)$ \\
\hline Successful & $652(69.7 \%)$ & $923(76.8 \%)$ & $1,575(73.7 \%)$ \\
Unsuccessful & $284(30.3 \%)$ & $279(23.2 \%)$ & $563(26.3 \%)$ \\
\hline Total & 936 & 1,202 & 2,138 \\
\hline
\end{tabular}




\section{Analyses}

Logistic regression was used to model the relationship of ATSAT score, controller age upon entering the FAA Academy, and the five-biodata items to training status of trainees assigned to an en route center or terminal facility. For both analyses, AT-SAT score and age were continuous variables. We excluded trainees with missing data on any of the variables entered into the model. There were 238 trainees with missing data. The final number of trainees included in the analyses was 1,900 (841 en route center trainees; 1,059 terminal facility trainees). Shown in Table 3 are the values and frequency counts for the biodata items entered into the logistic regression.

We entered the potential predictors into the logistic regression model in three blocks. We entered AT-SAT score and age in blocks one and two, respectively. The biodata items were entered in the third block using a forward stepwise selection method to enter the group. SPSS version 20 was used to conduct all analyses. We estimated the odds of successfully completing air traffic controller training at an en route center or terminal facility by AT-SAT score, age at entry on duty, and responses to the biodata items from the logistic regression equations.

\section{RESULTS}

\section{En Route}

For trainees assigned to an en route center, the initial logistic regression model of AT-SAT score, age at entry on duty, and biodata items on training status resulted in correct classifications of $64.6 \%$ of the trainees. An analysis of the data without 10 outliers (studentized residuals greater than 2.58 or less than -2.58) did not improve the model by more than two percentage points. Thus, we interpreted the original model with the outliers. A significant relationship was found between two of the assessed biodata items and training status after accounting for AT-SAT score and age, as indicated by the chi-square for the third block $\left(\chi^{2}(2)=21.48, p<.001\right)$. The overall model chi-square was also significant $\left(\chi^{2}(4)=66.62, p<.001,-2 L L=956.93\right)$. However, the predictors modeled only a small proportion of the variance in training success (Nagelkerke $R^{2}=.108$ ).

Table 3. Values and Frequency Counts for Predictor Variables by Facility Option

\begin{tabular}{l|r|r}
\hline BioData Item & En Route & Terminal \\
\hline HS GPA & $459(55 \%)$ & $591(56 \%)$ \\
B+ and Lower & $382(45 \%)$ & $468(44 \%)$ \\
A+ to A- & $346(41 \%)$ & $469(44 \%)$ \\
HS Math GPA & $495(59 \%)$ & $590(56 \%)$ \\
B+ and Lower & & \\
A+ to A- & $253(30 \%)$ & $388(37 \%)$ \\
Educational Degree & $121(14 \%)$ & $163(15 \%)$ \\
HS Diploma & $25(53 \%)$ & $493(47 \%)$ \\
Associates degree & $15(1 \%)$ \\
Bachelor's degree & & \\
Graduate degree & $25 \%)$ & $779(74 \%)$ \\
CTI Graduate & $584(69 \%)$ & $280(26 \%)$ \\
No & $257(31 \%)$ & $789(75 \%)$ \\
Yes & $625(74 \%)$ & $270(25 \%)$ \\
Pilot's Certificate & $224(26 \%)$ & \\
No & \\
Yes &
\end{tabular}




\begin{tabular}{|c|c|c|c|c|c|}
\hline & & \multirow[b]{4}{*}{$d f$} & \multicolumn{3}{|c|}{$95 \%$ CI for Odds Ratio } \\
\hline & \multirow[b]{3}{*}{$B(S E)$} & & Lower & Odds & Upper \\
\hline & & & & Ratio & \\
\hline & & & & & \\
\hline \multicolumn{6}{|l|}{ Included } \\
\hline Constant & $.29(1.37)$ & 1 & & & \\
\hline AT-SAT Score & $.05(.01)$ & 1 & 1.02 & 1.05 & 1.07 \\
\hline Age & $-.13(.03)$ & 1 & .83 & .87 & .92 \\
\hline HS Math GPA & $.67(.16)$ & 1 & 1.43 & 1.96 & 2.69 \\
\hline Pilot Certificate & $.36(.19)$ & 1 & 1.00 & 1.44 & 2.06 \\
\hline
\end{tabular}

Note: $R^{2}=10.02$ (Hosmer \& Lemeshow), .076 (Cox \& Snell), .108 (Nagelkerke). $\quad$ Model $\chi^{2}(4)=66.62$, $p<.001$.

Nevertheless, as shown in Table 4, the logistic regression coefficients for age, AT-SAT score, HS math GPA, and holding any pilot's certificate were statistically significant. The odds of successfully completing training and achieving CPC status were best for en route trainees that had scored high on ATSAT and were among the youngest trainees when they entered training. In addition, en route trainees that had reported on the biographical questionnaire that they had an A+ to A- HS math GPA and had held any pilot's certificate were more likely to succeed in training.

No relationship was found in this study between overall HS GPA, educational degree achieved, or being a CTI graduate and training status. We examined the model to determine if it met assumptions required for interpretation. To test the linearity of the logit, we ran the logistic regression analysis again, including predictors that were the interaction of each continuous variables and the $\log$ of itself (Field, 2009). The continuous variables were AT-SAT score and age. Neither interaction term was significant, meeting the assumption that the regression equation have a linear relationship with the logit form of the outcome measure. A second assumption, that the predictor variables not be correlated with one another, was also met, based on a test for multicolliearity using linear regression to obtain tolerance and variance inflation factor (VIF) values. As described in Field (2009), tolerance values less than .1 and VIF values larger than 10 may indicate a problem with collinearity. In our test for multicollinearity, all tolerance values were greater than .1, and VIF values were less than 10 . Thus, the model met assumptions required for interpretation.

\section{Terminal}

For trainees assigned to a terminal facility, the initial logistic regression model of AT-SAT score, age at entry on duty, and biodata items on training status resulted in correct classifications of $61.3 \%$ of the terminal trainees. An analysis of the data, with 13 outliers (studentized residuals greater than 2.58 or less than -2.58 ) removed, resulted in a model in which $64.1 \%$ of the trainees were correctly classified. However, in reviewing both regression models (with or without the outliers), we found that the same variables were included and excluded in the models. Thus, to be consistent with the previous analysis for en route trainees, we interpreted the regression model to include the outliers.

As stated, the logistic regression of AT-SAT score, age, and biodata items on training status resulted in correct classifications of $61.3 \%$. However, the only significant predictors were AT-SAT score and age. The model chi-square was significant $\left(\chi^{2}(2)=58.64, p<.001,-2 L L=1077.30\right)$. Similar to the model for en route trainees, the predictors modeled only a small proportion of the variance in training status (Nagelkerke $R^{2}=.082$ ). Nevertheless, as shown in Table 5, the logistic regression coefficients for AT-SAT score and age were statistically significant. The odds of successfully completing training and achieving CPC status were best for terminal trainees that had scored high on AT-SAT and were among the youngest trainees when they entered training.

There was no relationship between any of the biodata items and training status for the trainees assigned to a terminal facility. Again, we assessed assumptions of linearity and multicollinearity using the same procedures as described previously. The model met both assumptions.

Table 5. Predictors of Status in Terminal Training

\begin{tabular}{|c|c|c|c|c|c|}
\hline & \multirow{4}{*}{$B(S E)$} & \multirow{4}{*}{$d f$} & \multicolumn{3}{|c|}{$95 \%$ CI for Odds Ratio } \\
\hline & & & Lower & Odds & Upper \\
\hline & & & & Ratio & \\
\hline & & & & & \\
\hline \multicolumn{6}{|l|}{ Included } \\
\hline Constant & $1.27(1.29)$ & 1 & & & \\
\hline AT-SAT Score & $.05(.01)$ & 1 & 1.03 & 1.05 & 1.08 \\
\hline Age & $-.18(.03)$ & 1 & .80 & .84 & .88 \\
\hline
\end{tabular}




\section{DISCUSSION}

In the current research, we investigated the validity of five biodata items as predictors of controller training status after accounting for aptitude (e.g., AT-SAT score) and age at entry on duty for trainees assigned to en route centers and terminal facilities. As expected, we found AT-SAT score and age were related to training status for trainees assigned to both en route centers and terminal facilities. Younger trainees with higher AT-SAT scores succeeded in training more often than did older trainees with lower AT-SAT scores. In addition, and as expected, we found no relationship between level of educational degree and training status. Previous research has shown that in most cases, the level of educational degree does not predict who will or will not do well in training to be an air traffic controller (Cobb et al., 1976; Collins et al., 1990; VanDeventer et al., 1983).

It was somewhat surprising that we did not find high school GPA or having a degree from a CTI school to predict training status. It is possible that by including HS math GPA in this study, which we found to predict training status of en route trainees, we obscured the relationship between training status and high school GPA seen in previous research. It is also possible that the criterion measure used in this study, which differed from previous research studies, had an impact. In the research reported in VanDeventer et al. (1984), the criterion measure was success at the FAA Academy, whereas the criterion used in this study was success at the Academy and at the first facility. It is possible that high school GPA predicts Academy success, but is just simply less predictive of success in the field. The lack of a relationship between having a degree from a CTI school and training status is more difficult to understand. It was also somewhat surprising that, contrary to the results for en route trainees, we did not find any of the biodata items to relate to training status for trainees in terminal facilities.

\section{CTI Graduates}

One potential explanation for these findings is that CTI graduates were more likely than non-CTI graduates to be assigned to more complex facilities (e.g., en route centers and higher-level terminal facilities) and thus, less likely to succeed in training than non-CTI graduates. There were 537 CTI graduates in our sample of 1,900 trainees. The proportion of CTI graduates assigned to an en route center, rather than a terminal facility, was $47.9 \%$. Of the 1,363 non-CTI graduates in our sample, the proportion assigned to an en route center, rather than a terminal facility, was $42.8 \%$. The difference in assignment was significant $\left(\chi^{2}(1)=3.92, \mathrm{p}<.05\right)$. However, in examining how CTI and non-CTI graduates were assigned to high-level terminal facilities (levels 10-12) we found the relationship to be reversed. Of 1,059 trainees assigned to a terminal facility, 280 (26.4\%) were CTI graduates. Of those, $11.1 \%$ were assigned to high-level terminal facilities, whereas $17.7 \%$ of non-CTI graduates were assigned to high-level terminal facilities. This, too, was a statistically significant difference of $6.6 \%\left(\chi^{2}(1)=6.78, p<.01\right)$. However, with large sample sizes, such as we have here, even small differences may be statistically significant. The question is whether a difference in assignment of 5-7\% affected the extent to which CTI graduates were successful. Given that a having a CTI degree was not related to training performance in either the en route or terminal sample, it is unlikely that assignment differences had an effect on our results, despite the small, yet statistically significant differences in assignment.

A second explanation may be found in the CTI training program. There are 36 schools in the program, and except for a common core in aviation-education supplied and required by the FAA, the schools vary in what they teach and even how the information is taught. For example, some schools have an advanced radar simulation capability, allowing students to practice en route air traffic control skills, while other schools rely exclusively on classroom education. Previous research has shown that, independent of CTI programmatic differences, the selection rate for CTI graduates is higher than the selection rate for applicants from the general public. For example, in the Pierce et al. (2013a) study (which used a portion of the data used in this study), of the 2,090 CTI graduate applicants, $69 \%$ were selected, compared to $22 \%$ of the 12,034 non-CTI applicants. In addition, CTI graduates scoring in the "Qualified" rather than the "Well-Qualified" category were selected more often than similarly scoring non-CTI graduates. Thus, it is possible that training performance of CTI graduates was influenced by differences in the CTI programs and the processes used to select from the CTI applicants. We will need additional research to better understand the relationship between having a CTI degree and training performance.

\section{Option}

Results for the other biodata items, specifically HS math GPA and holding any pilot's certificate, differed between options. As predicted from prior research and as expected, we found HS math GPA and holding any pilot's certificate to relate to training status (Broach, 2012; Collins et al., 1990; Dean \& Broach, 2012; Pierce et al. 2013b; \& VanDeventer et al., 1984). However, in this study we found the same relationship to occur for trainees assigned to an en route center but not for trainees assigned to a terminal facility. 


\begin{tabular}{ll} 
Tower With Radar & $\begin{array}{l}\text { An airport traffic control terminal that provides traffic advisories, } \\
\text { spacing, sequencing and separation services to VFR and IFR } \\
\text { aircraft operating in the vicinity of the airport, using a combination } \\
\text { of radar and direct observations. }\end{array}$ \\
& $\begin{array}{l}\text { An airport traffic control terminal that provides radar-control } \\
\text { service to aircraft arriving or departing the primary airport and } \\
\text { adjacent airports, and to aircraft transiting the terminal's airspace. }\end{array}$ \\
TRACON & $\begin{array}{l}\text { An airport traffic control terminal that provides both direct } \\
\text { observations and radar-control service to aircraft arriving or } \\
\text { departing the primary airport and adjacent airports, and to aircraft } \\
\text { transiting the terminal's airspace. The terminal is divided into two } \\
\text { and Tower With Radar } \\
\text { functional areas: radar approach control positions and tower } \\
\text { positions. These two areas are located within the same facility, or } \\
\text { in close proximity to one another, and controllers rotate between } \\
\text { both areas. }\end{array}$ \\
\hline
\end{tabular}

Table 7. Training Status by Terminal Facility Type

\begin{tabular}{lccc}
\hline Outcome & $\begin{array}{c}\text { Tower } \\
(n=365)\end{array}$ & $\begin{array}{c}\text { Tower/TRACON } \\
(n=564)\end{array}$ & $\begin{array}{c}\text { TRACON } \\
(n=130)\end{array}$ \\
\hline Successful & $311(85.2 \%)$ & $435(77.1 \%)$ & $72(55.4 \%)$ \\
Unsuccessful & $54(14.8 \%)$ & $129(22.9 \%)$ & $58(44.6 \%)$ \\
\hline
\end{tabular}

A possible explanation for the results may be due to heterogeneity of facilities within the terminal option. Most terminal facilities fall into one of three categories: tower with radar (referred to as airport traffic control towers), TRACON, or combination tower, and TRACON. A brief description extracted from the FAA's controller workforce plan (FAA, 2014) is provided in Table 6 (also see Broach, 2013). Tower controllers primarily use visual means to control aircraft arriving and departing an airport. Tower controllers also control movement of aircraft at the airport. TRACON controllers use radar to control aircraft in the terminal airspace, approximately 5 to 40 miles from an airport and below an altitude of 10,000 feet. Controllers in these stand-alone TRACONs may be responsible for air traffic flying into and out of multiple airports. Controllers in a combination tower and TRACON facility use both visual means and radar to control traffic within their terminal airspace. In combination facilities, often referred to as up/down facilities, controllers learn to control air traffic using visual means in the tower and radar in the TRACON. In this type of facility, the TRACON is often located below the tower, hence the name up/down.

Results from job analyses have indicated that the aptitudes (work requirements) required to control air traffic are similar across option (en route and terminal) and facility types within the terminal option (Nickels, Bobko, Blair, Sands, \& Tartak, 1995). Aptitudes are "innate and learned abilities and other personal characteristics required of a person at the time of hire and for which the employer (the FAA) provides no specific training or development" (Broach, 2013, p. 2). However, we found that the likelihood that a trainee would succeed in terminal training varied greatly by terminal facility type. As shown in Table 7, the proportion of successful trainees decreased from tower to tower/TRACON to TRACON facilities. In other words, trainees assigned to the terminal option were most likely to succeed if placed in a tower facility and least likely to succeed if placed in a TRACON facility.

A chi-square analysis indicated that this difference was significant. There was a significant association between terminal facility type and training status $\left(\chi^{2}(2)=48.50\right.$, $p<.001)$. Differences existed between each facility type: tower and tower/TRACON $\left(\chi^{2}(1)=9.14, p<.002\right)$, tower/ TRACON and TRACON $\left(\chi^{2}(2)=25.37, p<.001\right)$, and tower and TRACON $\left(\chi^{2}(1)=48.69, p<.001\right)$. These differences may have interfered with our ability to identify biodata items predictive of training status for trainees assigned to the terminal option. Future, researchers may want to examine more closely the terminal option to determine if it is possible to identify predictors that differentiate training success of new hires by facility type.

\section{Limitation}

A limitation of this research was the use of only one criterion measure related to training status. There is a need to consider multiple outcome measures, especially measures related to onthe-job performance of air traffic controllers. Ultimately, the goal is to select, place, and train successful air traffic controllers, not merely identify candidates likely to succeed in training. 


\section{CONCLUSIONS}

Our findings are somewhat consistent with previous research, especially our findings regarding predictors of success in training as an en route controller. Our findings also provide additional support for the utility and validity of AT-SAT in predicting training status of trainees (Broach et al., 2013). Our results demonstrated yet again an inverse relationship between age at entry on duty and training performance. Younger controllers performed better in training than did older controllers. The current maximum age at entry on duty as a controller is 31 . The FAA makes exceptions to the age policy for retired military controllers and previous FAA controllers. For the majority of new hires from groups such as the general public, CTI graduates, and even former military controllers, an applicant must not have reached his or her $31^{\text {st }}$ birthday to be eligible for hire into controller occupation. Although the FAA cannot use age for controller selection, our results support continuation of the entry on duty age policy.

\section{Quality Ranking Factors}

Finally, regarding the quality ranking factors proposed by the independent review panel to select candidate controllers, the research evidence is mixed. QRFs in selection under federal civil service rules are factors "expected to significantly enhance performance in a position" (FAA, 2012).

College Degree. First, based on our analyses, we recommend that the FAA not use having a college degree as a QRF in selection. Having a college degree was not a significant predictor in either of the current models. Trainees with college degrees are no more likely to succeed in controller training than trainees without college degrees. This finding is consistent with previous research in which there was either no or an inverse relationship found between having a college degree and controller performance (Cobb et al., 1976; Collins, et al., 1990). Thus, we conclude that having a college degree does not significantly enhance performance and, therefore, should not be a quality-ranking factor, as defined by the FAA.

CTI Graduates. Additional research is needed to understand the relationship between being a CTI graduate and training status. A question is whether graduates from some CTI schools are more likely to succeed in training than graduates from other CTI schools. Are programmatic differences among the schools obscuring the relationship between having a CTI degree and success in ATC training? We recommend that a follow-on to this study be conducted in which differences among CTI programs be examined in relationship to ATC training success. Although such a study may be hampered by unequal and even underrepresentation from certain CTI schools, it might be possible to group schools based on programmatic differences, as noted by the IRP (Barr et al., 2011). The IRP recommended such a study as a necessary pre-condition for making selection decisions based on CTI school programmatics.

Pilot Certificate. Regarding previous experience as a pilot, we did find that having a pilot's certificate predicted training status of trainees assigned to an en route facility, but not for trainees assigned to a terminal facility. However, differences among terminal facilities may have obscured any possible relationship. This warrants further investigation before holding a pilot's certificate is implemented as a hiring QRF. The Pierce et al. (2013b) study found a relationship between having a pilot's certificate and previous experience in air traffic control, but the relationship was found for controllers in training more than 20 years ago and without accounting for AT-SAT score and age. Regarding the other experience factors proposed by the IRP (flight instructor, aircraft dispatcher, flight navigator, aircraft mechanic, and air traffic controller), we were unable able to evaluate them because too few trainees indicated having those experiences when they took the BQ or because they were prior military controllers and had not taken the AT-SAT.

\section{Biodata Usefullness}

This is the first study using recently hired controllers that has examined the utility of biodata in hiring air traffic controllers, after accounting for AT-SAT score and age at entry on duty. Our goal was to determine if the experiences assessed by the biodata items would contribute to the prediction of controller training status, over and above AT-SAT score and age at entry on duty. We concluded that, after screening applicants based on age and selecting only those who passed the AT-SAT test battery, the biodata items assessed did little to improve our ability to select the applicants most likely to reach CPC. If biodata are to be used to select controllers, additional research is required to identify those biodata items that will add to the prediction of controller training performance over and above the effect of AT-SAT score and age.

\section{REFERENCES}

Barr, M., Brady, T., Koleszar, G., New, M., \& Pounds, J. (September 22, 2011). FAA Independent Review Panel on the Selection, Assignment and Training of Air Traffic Control Specialists. Washington, DC: FAA. Retrieved from http://www.faa.gov/news/updates/media/IRP\%20 Report\%20on\%20Selection\%20Assignment $\% 20$ Training\%20of\%20ATCS\%20FINAL\%2020110922.pdf

Bobko, P., \& Roth, P.L. (2013). Reviewing, categorizing, and analyzing the literature on black-white mean differences for predictors of job performance: Verifying some perceptions and updating/correcting others. Personnel Psychology, 66, 91-126.

Breaugh, J.A. (2009). The use of biodata for employee selection: Past research and future directions. Human Resource Management Review, 19, 219-231.

Broach, D. (2012). Incremental validity of biographical data in the prediction of en route air traffic control specialist technical skills (Report No. DOT/FAA/AM-12/8). Washington, DC: FAA Office of Aerospace Medicine. 
Broach, D. (2013). Selection of the next generation of air traffic control specialists: Aptitude requirements for the air traffic control tower cab in 2018 (Report No. DOT/FAA/ AM-13/5). Washington, DC: FAA Office of Aerospace Medicine.

Broach, D., Byrne, C.L., Manning, C.A., Pierce, L., McCauley, D., \& Bleckley, M.K. (2013). The validity of the air traffic selection and training (AT-SAT) test battery in operational use (Report No. DOT/FAA/AM-13/3). Washington, DC: FAA Office of Aerospace Medicine.

Cobb, B.B., Lay, C.D., \& Bourdet, N.M.. (1971). The relationship between chronological age and aptitude test measures of advanced-level air traffic control trainees (Report No. DOT/FAA/AM-71/36). Washington, DC: FAA Office of Aviation Medicine.

Cobb, B.B., \& Nelson, B.A. (1974). Aircraft-pilot and other pre-employment experience as factors in the selection of air traffic controller trainees (Report No. DOT/FAA/ AM-74/8). Washington, DC: FAA Office of Aviation Medicine.

Cobb, B.B.,Young, C.L., and Rizzuti, B.L. (1976). Education as a factor in the selection of air traffic controller trainees (Report No. DOT/FAA/AM-76/6). Washington, DC: FAA Office of Aviation Medicine.

Collins, W.E., Boone, J.O., \& VanDeventer, A.D. (1981). The selection of air traffic control specialists: History and review of contributions by the civil aeromedical institute. Aviation, Space, and Environmental Medicine, 52, $217-$ 240 .

Collins, W.E., Nye, L.G., \& Manning, C.A. (1990). Studies of poststrike air traffic control specialist trainees: III. Changes in demographic characteristics of academy entrants and biodemographic predictors of success in air traffic controller selection and academy screening (Report No. DOT/FAA/ AM-90/4). Washington, DC: FAA Office of Aviation Medicine.

Dean, M., \& Broach, D. (2012). Development, validation, and fairness of a biographical data questionnaire for the air traffic control specialist occupation (Report No. DOT/ FAA/AM-12/19). Washington, DC: FAA Office of Aerospace Medicine.

Dean, M.A., \& Russell, C.J. (2005). An examination of biodata theory-based constructs in a field context. International Journal of Selection and Assessment, 13, 139-149.

Farmer, W.L. (2002). Characteristics of biodata keys as function of scaling method, sample size, and criterion (Unpublished doctoral dissertation). Norman, OK: University of Oklahoma.
Federal Aviation Administration (2011, May). National Training Database Guidelines. Washington, DC: FAA.

Federal Aviation Administration. (2012). Human resources policy manual (HRPM): EMP-1.28. Category ranking. Washington, DC: Author. Last retrieved September 6, 2013 from https://employees.faa.gov/org/staffoffices/ahr/ program_policies/policy_guidance/hr_policies/hrpm/ emp/emp-1-28/media/EMP12804122012.pdf

Federal Aviation Administration (2014). A plan for the future: 10-year strategy for the air traffic control workforce 20142023. Washington, DC; FAA.

Field, A. (2009). Discovering statistics using SPSS (3rd ed.). London: SAGE.

Hough, L.M., Oswald, F.L., \& Ployhart, R.E. (2001). Determinants, detection and amelioration of adverse impact in personnel selection procedures: Issues, evidence and lessons learned. International Journal of Selection and Assessment, 9, 152-194.

Heil, M.C. (1999a). An investigation of the relationship between chronological age and job performance for incumbent air traffic control specialists (Report No. DOT/FAA/AM-99/18). Washington, DC: FAA Office of Aviation Medicine.

Heil, M.C. (1999b). Air traffic control specialist age and cognitive test performance (Report No. DOT/FAA/ AM-99/23). Washington, DC: FAA Office of Aviation Medicine.

Imus, A., Schmitt, N., Kim, B., Oswald, F.L., Merritt, S., \& Wrestring, A.F. (2011). Differential item functioning in biodata: Opportunity access as an explanation of genderand race-related DIF. Applied Measurement in Education, 24, 71-94.

Mumford, M.D., \& Whetzel, D.L. (1997). Background data. In D.L. Whetzel \& G.R. Wheaton (Eds.), Applied measurement in industrial and organizational psychology (pp. 58-84). Palo Alto, CA: Consulting Psychologists Press.

Mumford, M.D., Barrett, J.D., \& Hester, K.S. (2012). Background data: Use of experiential knowledge in personnel selection. In Neal Schmitt (Ed.), The oxford handbook of personnel assessment and selection (pp. 353-382). New York, NY: Oxford University Press.

Nickels, B.J., Bobko, P., Blair, M.D., Sands, W.A., \& Tartak, E.L. (1995). Separation and Control Hiring Assessment (SACHA) final job analysis report. (Deliverable Item 007A under FAA contract DTFA01-91-C-00032.) Washington, DC: FAA Office of the Assistant Administrator for Human Resources Management. 
Nye, L.G., Schroeder, D.J., \& Dollar, C.S. (1994). Relationships of type a behavior with biographical characteristics and training performance of air traffic controllers (Report No. DOT/FAA/AM-94/13). Washington, DC: FAA Office of Aviation Medicine.

Outtz, J.L., \& Hanges, P.J. (2012). Barrier analysis of the Air Traffic Control Specialists (ATCS) centralized hiring process. Octoer 19, 2012. Retrieved from http://www.faa.gov/ about/office_org/headquarters_offices/acr/eeo_affirm_ program/media/Barrier_Analysis_Report.pdf

Pierce, L.G., Bleckley, M.K., \& Crayton, L. (2013a). The utility of AT-SAT in hiring graduates of an air trafficcollegiate training initiative program. (Report No. DOT/ FAA/AM-13/11). Washington, DC: FAA Office of Aerospace Medicine.

Pierce, L.G. Williams, C.A., Broach, D., \& Bleckley, M.K. (2013b). Assessing prior experiences in the selection of air traffic control specialists (Report No. DOT/FAA/

AM-13/7). Washington, DC: FAA Office of Aerospace Medicine.

Ramos, R.A., Heil, M.C., \& Manning, C.A. (Eds.) (2001a). Documentation of validity for the AT-SAT computerized test battery, Volume I. (Report No. DOT/FAA/AM-01/5). Washington, DC: Federal Aviation Administration Office of Aviation Medicine.
Ramos, R.A., Heil, M.C., \& Manning, C.A. (Eds.) (2001b). Documentation of validity for the AT-SAT computerized test battery, Volume II. (Report No. DOT/FAA/AM-01/6). Washington, DC: Federal Aviation Administration Office of Aviation Medicine.

Schmidt, F.L., \& Hunter, J.E. (1998). The validity and utility of selection methods in personnel psychology: Practical and theoretical implications of 85 years of research findings. Psychological Bulletin, 124, 262-274.

Sinha, R., Oswald, R., Imus, A., \& Schmitt, N. (2011). Criterion-focused approach to reducing adverse impact in college admissions. Applied Measurement in Education, 24, 137-161.

Stokes, G. (1999). Introduction to special issue: The next one hundred years of biodata. Human Resource Management Review, 9, 111-116.

VanDeventer, A.D., Collins, W.E., Manning, C.A., Taylor, D.K., \& Baxter, N.E. (1984). Studies of poststrike air traffic control specialist trainees: I. Age, biographic factors, and selection test performance related to Academy training success (Report No. DOT/FAA/AM-84/6). Washington, DC: FAA Office of Aviation Medicine.

VanDeventer, A.D., Taylor, D.K., Collins, W.E., \& Boone, J.O. (1983). Three studies of biographical factors associated with success in air traffic control specialist screen/training at the FAA Academy (Report No. DOT/FAA/AM-83/6). Washington, DC: FAA Office of Aviation Medicine. 
